\title{
Avoiding OHSS: Controlled Ovarian Low-Dose Stimulation in Women with PCOS
}

\author{
Vermeidung eines OHSS: kontrollierte ovarielle Low-Dose-Stimulation \\ für IVF und ICSI bei Frauen mit polyzystischem Ovarsyndrom
}

Authors

Affiliations
D. Fischer ${ }^{1}$, C. Reisenbüchler ${ }^{1}$, S. Rösner ${ }^{2}$, J. Haussmann ${ }^{1}$, P. Wimberger ${ }^{1}$, M. Goeckenjan ${ }^{1}$

${ }^{1}$ University Hospital of Gynecology and Obstetrics, Technical University, Dresden

${ }^{2}$ University Hospital of Heidelberg, Department of Gynecological Endocrinology and Reproductive Medicine, Heidelberg

Key words
PCOS
IVF/ICSI
ART
ovarian hyperstimulation
syndrome (OHSS)
gonadotropins
Schlüsselwörter
PCOS
IVF/ICSI
künstliche Befruchtung
ovarielles Überstimulations-
syndrom (OHSS)
Gonadotropin

received 9.10.2015 revised 19.12 .2015 accepted 24.12.2015

Bibliography

DOI http://dx.doi.org/

10.1055/s-0042-100206

Geburtsh Frauenheilk 2016; 76:

718-726 @ Georg Thieme

Verlag KG Stuttgart - New York . ISSN 0016-5751

\section{Correspondence}

Dr. Maren Goeckenjan, MD

University Hospital of

Technical University

Department of Gynecology

and Obstetrics

Fetscherstraße 74

01307 Dresden

maren.goeckenjan@

uniklinikum-dresden.de

\section{Abstract \\ $\nabla$}

The polycystic ovary syndrome is a common endocrine disorder which influences outcome and potential risks involved with controlled ovarian stimulation for artificial reproductive techniques (ART). Concrete practical recommendations for the dosage of gonadotropins, the preferred protocol and preventive methods to avoid ovarian hyperstimulation syndrome (OHSS) are lacking. We present retrospective data of 235 individually calculated gonadotropin low-dose stimulations for ART in a single center from 2012 to 2014 . Clinical data and outcome parameter of patients diagnosed with PCOS according to Rotterdam criteria $(\mathrm{n}=39)$ were compared with patients without PCOS $(n=196)$. The starting dose of gonadotropins was individually calculated depending on patients' age, BMI, ovarian reserve, ovarian response in previous cycles, and diagnostic criteria of PCOS. Mean age and duration of infertility did not differ between the groups, whereas mean BMI $(p=0.007)$ and AMH $(p<0.001)$ were higher in the PCOS-group. A lower mean FSH-starting and maximum dose was administered to women with PCOS ( $p<0.001)$. The biochemical pregnancy rate of $42.4 \%$ and the clinical pregnancy rate of $32.2 \%$ for PCOS-patients did not differ from those of the control group ( $42.2 \%$ and $34.4 \%$ respectively). Neither mild, nor moderate or severe manifestation of OHSS occurred significantly more often in patients with PCOS. Our study supports the use of a calculated low-dose FSH-stimulation strategy in ART for patients with PCOS. Further randomized clinical trials should confirm this strategy and lead to define individual risk factors for OHSS, which can be used for recommendation of safer ART-techniques like in vitro maturation.

\section{Zusammenfassung \\ $\nabla$}

Das polyzystische Ovarsyndrom (PCOS) ist eine häufige endokrinologische Störung der Frau, die erhebliche Auswirkungen auf Erfolg und potenzielle Risiken einer Gonadotropinstimulation bei künstlicher Befruchtung hat. Klare praktische Empfehlungen für die FSH-Dosierung und das optimale Stimulationsprotokoll zur Vermeidung eines OHSS fehlen weitgehend. Retrospektiv wurden Zyklen von 235 Patientinnen, die von 2012 bis 2014 für eine IVF/ICSI kontrolliert stimuliert wurden, analysiert. Klinische Daten der PCOS-Patientinnen $(n=39)$ wurden mit denen ohne PCOS $(n=196)$ verglichen. Die Gonadotropin-Startdosierung orientierte sich am Alter der Patientinnen, dem BMI, der ovariellen Reserve, Stimulationsverläufen in Vorzyklen und diagnostischen Kriterien des PCOS. Durchschnittliches Alter und Dauer der Infertilität unterschieden sich nicht signifikant zwischen den beiden Gruppen. Der durchschnittliche BMI $(p=0,007)$ und basale AMH-Wert $(\mathrm{p}<0,001)$ lag bei Frauen mit PCOS höher. Bei ihnen fand sich eine signifikant niedrigere FSH-Start- und Maximaldosis ( $\mathrm{p}<0,001$ ). Die Gesamtdosis verwendeter Gonadotropineinheiten sowie der maximale Östradiolspiegel jedoch unterschieden sich nicht. Auch die biochemischen und klinischen Schwangerschaftsraten von 42,2 und $32,2 \%$ bei PCOS-Patientinnen wichen nicht signifikant von den Ergebnissen der Kontrollgruppe ab $(42,2$ und 34,4\%). Weder leichte noch moderate oder schwere Ausprägungen des OHSS kamen häufiger in einer der beiden Gruppen vor. Unsere Studie schlägt eine kalkulierte, niedrigdosierte Stimulationsstrategie mit Dosissteigerung in kleinen Schritten vor. Durch weitere randomisierte, kontrollierte klinische Studie sollte diese Strategie überprüft werden und individuelle Risikofaktoren erkannt werden, die in Einzelfällen als Indikation zu anderen sicheren Methoden der ART wie der In-vitro-Maturation genutzt werden können. 


\section{Introduction}

\section{$\nabla$}

The polycystic ovary syndrome (PCOS) is the most common endocrine disorder of women in reproductive age [1]. It causes chronic oligo- or anovulation and often leads to infertility. Inclusive diagnostic criteria were established 2003 in Rotterdam. The criteria provide opportunities to distinguish four clinical phenotypes using at least two of three criteria to define the syndrome: hyperandrogenism defined either as hyperandrogenaemia or clinically validated hyperandrogenism, oligo- or anovulation, and polycystic ovarian morphology in ultrasound [2]. Geisthövel proposed a further classification of women with PCOS mainly using the diagnostic aspect of hyperandrogenism. He defined five clinical subgroups: functional cutaneous androgenisation (FCA) and four typical manifestations of the female androgenisation syndrome (FAS) I-IV [3]. This approach includes a slightly different group of women than using the Rotterdam criteria for PCOS. Especially women with late onset adrenogenital syndrome or other adrenal origin of hyperandrogenaemia are included in this classification, which are explicitly excluded in the PCOS definition.

Controlled ovarian hyperstimulation (COS) with gonadotropins for artificial reproductive techniques (ART) leads to a higher risk of ovarian hyperstimulation syndrome (OHSS) for patients affected by PCOS, because of a higher sensibility and exaggerated response to gonadotropins [4].

Therefore, it is important to give recommendations for the dosage and the preferred stimulation-protocol to avoid ovarian hyperstimulation syndrome (OHSS). So far, clear guidelines from health institutes and PCOS societies or in scientific literature are lacking.

It is current practice to use the antagonist protocol to avoid OHSS in patients with elevated risk, mainly due to the possibility to use the GnRH-agonist for ovulation induction and cryopreserve all fertilised oocytes or embryos ("freeze all") [5]. Most published studies use equal doses of gonadotropins for stimulation of patients with or without PCOS. Others propose fixed doses or lack to describe how to individualize dose and regimen. A biographical search of the MEDLINE database was performed in March 2014 and June 2015. The MESH words "PCO" and "IVF", "controlled ovarian stimulation", "FSH" were used. Articles prior to the year 2005, those without an abstract or those that were written in a language other than English, German or French were excluded ( Table 1$)$.

Clear recommendations for the FSH dosage and protocol should be established to improve outcome and security of controlled ovarian stimulation in a group of ART-patients with special demands.

A modern approach to classify the ovarian response or sensitivity to gonadotropin stimulation in PCOS patients is the evaluation of risks using the levels of AMH [6]. According to this classification, non-responders show basal AMH-values lower than $0.154 \mathrm{ng} / \mathrm{ml}$, poor responders $0.154-0.7 \mathrm{ng} / \mathrm{ml}$, normal responders 0.71 $2.1 \mathrm{ng} / \mathrm{ml}$ and high responders above $2.11 \mathrm{ng} / \mathrm{ml}$. Lee et al. further subdivided the group of high responders by introducing excessive responders with basal values above $3.35 \mathrm{ng} / \mathrm{ml}$ [7].

\section{Aims of the study}

The goal of this study was to compare pregnancy rates and complication rates, especially the occurrence of OHSS, under a lower, individualized gonadotrophin dosing mainly in the long agonist protocol in a clinical setting.

\section{Materials und Methods \\ $\nabla$}

This study was designed as a single center retrospective clinical study. Data of cycles of controlled ovarian stimulation for IVF/ICSI were analyzed according to the criteria of PCOS.

\section{Study population}

We analyzed all stimulation cycles for IVF/ICSI of patients within three years, from 01.01.2012 to 31.12.2014, who were performed at the fertility center of the University Hospital, Department of Gynecology and Obstetrics of the Technical University of Dresden, Germany. With consent of the institutional ethics committee and written informed consent of the patients, 370 cycles of 235 women were reviewed, focusing on diagnosis of PCOS. Those patients with PCOS $(n=39)$ constitute the study population, while all other women $(n=196)$ serve as control group.

\section{Inclusion criteria}

According to the inclusive Rotterdam Criteria (Rotterdam ESHRE/ ASRM-Sponsored PCOS consensus workshop group, 2004), we included women with at least two out of three following characteristics:

- Hyperandrogenemia (at least one of the androgens above the 95th percentile: free testosterone, androgen-index, androstenedione and DHEAS)

- Report of oligomenorrhea with cycle length of more than 35 days, amenorrhea with cycles lasting longer than three months or absence of a rise of progesterone before menstruation during cycle monitoring

- Documented polycystic ovarian morphology by an experienced sonographer or visualization of polycystic ovaries according to Rotterdam Criteria on printed pictures (more than 12 small antral follicles of 2-9 mm size in one ovary)

\section{Exclusion criteria}

All women stimulated were analyzed. The study group consisted of women with diagnosis of PCOS. Patients with clinical signs of PCOS but additional diagnosis of clinical thyroid dysfunction, early or late onset adrenogenital syndrome (AGS), androgen producing neoplasm, Cushing's syndrome, hypogonadotrophic hypogonadism, premature ovarian failure, hyperprolactinaemia, HAIRAN-syndrome or intake of exogenous androgens were not regarded as PCOS according to Rotterdam criteria [2].

Six patients fulfilling diagnostic criteria of PCOS were not included in the study group, three because of the diagnosis of Hashimoto's thyroiditis, two patients exhibited hypogonadotrophic hypogonadism and one woman was diagnosed with late onset AGS. One patient underwent stimulation without fertilization of oocytes for purpose of fertility preservation and two others had missing clinical data and were not included in the PCOS-study group.

\section{Data collection}

A total of 235 couples underwent ART in our center and were analyzed for the study. Prior to treatment three diagnostic appointments consisting of cycle monitoring, hormone profile and transvaginal ultrasound were used to exclude anatomical malformation, assess AFC and confirm ovulation. The medical history was taken separately for each partner and at least one sperm count was analyzed according to WHO criteria from 2010 [8].

OHSS was scored according to the classification of Aboulghar und Mansour [9]. A mild manifestation is characterized by mild 
Table 1 Comparison of studies on controlled ovarian stimulation with FSH in recent studies of the last 10 years.

\begin{tabular}{|c|c|c|c|}
\hline Reference & Study & FSH starting dose for PCOS & Recommendation for dose adjustment \\
\hline $\begin{array}{l}\text { Palep-Singh } \\
\text { et al., } 2007\end{array}$ & $\begin{array}{l}\text { Observational comparative study (PCOS in } \\
\text { Asian women } n=104 \text {, Caucasian } n=220 \text {, } \\
\text { controls } n=284 \text { ) }\end{array}$ & $\begin{array}{l}\text { Mean starting dose } \\
150 \text { IU for Asian PCOS } \\
200 \text { IU for Caucasian PCOS } \\
225 \text { IU for Asian and Caucasian } \\
\text { tubal infertility }\end{array}$ & $\begin{array}{l}\text { Adjustment according to age, basal FSH and BMI, } \\
\text { after } 7 \text { days possible increase of dosage in case of } \\
\text { suboptimal response }\end{array}$ \\
\hline $\begin{array}{l}\text { Weghofer } \\
\text { et al., } 2007\end{array}$ & $\begin{array}{l}\text { Retrospective cohort study of } 47 \text { women } \\
\text { with PCOS compared to } 100 \text { controls }\end{array}$ & $\begin{array}{l}150-450 \text { IU for PCOS and } \\
\text { Non-PCOS }\end{array}$ & Adjustment to follicular response \\
\hline $\begin{array}{l}\text { Koundouros } \\
\text { et al., } 2008\end{array}$ & $\begin{array}{l}\text { Prospective randomized study with } \\
\text { PCOS-patients }(n=225)\end{array}$ & $\begin{array}{l}75 \mathrm{IU} / \mathrm{d} \text { step up } \\
225 \mathrm{IU} / \mathrm{d} \text { step down } \\
150 \mathrm{IU} \text { and individual } \\
\text { adjustment }\end{array}$ & $\begin{array}{l}\text { Step-up regimen: } 75 \mathrm{IU} / \mathrm{d} \text { for } 6 \text { days, then increase } \\
\text { of } 37.5 \mathrm{IU} \\
\text { Step-down: } 225 \mathrm{IU} / \mathrm{d} \text { of FSH for the first } 3 \text { days } \\
\text { followed, then decrease to } 150 \mathrm{IU} / \mathrm{d} \text { for the next } 3 \\
\text { days, then decreased to } 75 \mathrm{IU} / \mathrm{d} \text { or sustain at } 150 \mathrm{IU} \\
\text { Step-up/Step-down: } 150 \mathrm{IU} \text { on day } 1 \text {, then decrease } \\
\text { to } 75 \mathrm{IU} \text { on day } 2 \text {, then increase back to } 150 \mathrm{IU} \text { and } \\
\text { so on until day } 6 \text {, then, sustain at } 150 \mathrm{IU} / \mathrm{d} \text { or } 75 \mathrm{IU} / \mathrm{d}\end{array}$ \\
\hline $\begin{array}{l}\text { Sahu et al., } \\
2008\end{array}$ & $\begin{array}{l}\text { Retrospective analysis of } 51 \text { PCOS ART-cycles, } \\
\text { compared to } 50 \text { cycles with ultrasound } \\
\text { morphology of PCO, control group } 104 \text { cycles }\end{array}$ & $300 \mathrm{IU}$ & $\begin{array}{l}\text { According ovarian reserve score } \\
\text { (age, BMI, AFC, FSH, E2), control on day } 4\end{array}$ \\
\hline $\begin{array}{l}\text { Swanton et al., } \\
2010\end{array}$ & $\begin{array}{l}\text { Prospective cohort study ( } n=290 \text { women, } \\
\text { including PCOS } n=78, \text { PCO } n=101 \text { and } \\
\text { control } n=101)\end{array}$ & $\begin{array}{l}150-375 \text { IU according to age, } \\
\text { basal FSH and previous ovarian } \\
\text { response to gonadotropins - } \\
\text { no difference in PCOS, PCO }\end{array}$ & No adjustment described \\
\hline $\begin{array}{l}\text { Ashrafi et al., } \\
2011\end{array}$ & $\begin{array}{l}\text { Controlled randomized prospective study } \\
\text { with } n=90 \text { women with PCOS - three } \\
\text { protocol variations concerning type of } \\
\text { gonadotropins given and dose adjustment }\end{array}$ & 150 IU for PCOS in all groups & $\begin{array}{l}\text { Fixed dose of } 150 \mathrm{IE} \\
\text { Step down protocol to } 75 \mathrm{IU} \text {, when leading follicle } \\
\text { reached } 14 \mathrm{~mm} \text { in diameter } \\
\text { FSH discontinued and low dose HCG when leading } \\
\text { follicle } 14 \mathrm{~mm}\end{array}$ \\
\hline $\begin{array}{l}\text { Decanter et al., } \\
2013\end{array}$ & $\begin{array}{l}\text { Single center prospective non-randomized } \\
\text { interventional study }(n=113) \text {. Intervention } \\
\text { was pretreatment with oral contraceptives }\end{array}$ & $\begin{array}{l}100 \text { to } 200 \mathrm{IU} \text {, according to age, } \\
\mathrm{BMI} \text { and } \mathrm{AFC}\end{array}$ & No adjustment described \\
\hline $\begin{array}{l}\text { Huber et al., } \\
2013\end{array}$ & $\begin{array}{l}\text { Retrospective cross-sectional study } \\
\text { with } n=7520 \text { cycles, mixed cohort, } \\
\text { no recommendation for PCOS }\end{array}$ & $\begin{array}{l}\text { Mixed cohort, } 75-450 \text { IU; } 75-125 \text { IE } \\
\text { for expected high response, } \\
150-225 \text { IU for normal response } \\
300-450 \text { IU for poor response, } \\
\text { according to age, markers of ovarian } \\
\text { reserve, BMI, and previous response }\end{array}$ & $\begin{array}{l}\text { Individual adjustment to response } \\
\text { No recommendation for PCOS }\end{array}$ \\
\hline $\begin{array}{l}\text { Figen Turkcapar } \\
\text { et al., } 2013\end{array}$ & $\begin{array}{l}\text { Prospective randomized controlled study } \\
\text { ( } n=80 \text { women with PCOS), HMG vs. FSH } \\
\text { stimulation }\end{array}$ & $150 \mathrm{IU}$ & $\begin{array}{l}\text { Adjustment according to E2, sonographical } \\
\text { response }\end{array}$ \\
\hline $\begin{array}{l}\text { Akpinar et al., } \\
2014\end{array}$ & $\begin{array}{l}\text { Retrospective observational study of } n=337 \\
\text { cycles of women with PCOS }\end{array}$ & 75-300 IU according to BMI & No adjustment described \\
\hline $\begin{array}{l}\text { Shi et al., } \\
2014\end{array}$ & $\begin{array}{l}\text { Multicenter prospective randomized con- } \\
\text { trolled study of } 1180 \text { women with PCOS. } \\
\text { Intervention randomized in fresh ET at } \\
\text { day } 3 \text { or freeze all }\end{array}$ & $\begin{array}{l}112.5 \mathrm{IU} / \text { day for patients } \leq 60 \mathrm{~kg} \\
\text { for PCOS } \\
150 \mathrm{IU} / \text { day for patients }>60 \mathrm{~kg} \\
\text { for PCOS }\end{array}$ & Adjustment according to ovarian response \\
\hline
\end{tabular}

symptoms, abdominal pain or distension and enlarged ovaries but no visible fluids in the pouch of Douglas on ultrasound scan. Moderate OHSS appears with sonographic evidence of ascites accompanying further symptoms but without shift of haemostaseological or biochemical serum parameters. In case of disarrangement of hemostasis, elevated liver enzymes, haematoconcentration, elevated creatinin, dyspnea, oliguria, massive ascites or pleural effusion, severe hyperstimulation is present.

\section{Intervention}

For GnRH-agonist protocol, Nafarelin (Synarela ${ }^{\circledR}$, Pharmacia, Copenhagen, Denmark), Triptorelin (Decapaptyl ${ }^{\circledR}$, Ipsen Pharma, Barcelona, Spain, or as Depot: Ferring Arzneimittel GmbH, Kiel, Germany) or Leuprorelin (Enantone ${ }^{\circledR}$, Takeda Pharmaceutical Company Limited, Osaka, Japan) were used for the purposes of downregulation. In some cases, an oral contraceptive pill was giv- en for one cycle overlapping with the agonist downregulation or before the start of stimulation in antagonist cycles, predominantly $30 \mu \mathrm{g}$ ethinylestradiol and $125 \mu \mathrm{g}$ levonorgestrel (Minisiston $^{\circledR}$ ). Cetrotide ${ }^{\circledR}$ (Merck Serono, MSD, the Netherlands) or Ganirelix (Orgalutran ${ }^{\circledR}$, Organon, Skovlunde, Denmark) were injected in the multidose flexible antagonist-protocol.

We used recombinant FSH Gonal-F ${ }^{\circledR}$ (Serono Pharmaceuticals Ltd., Feltham, UK), Puregon ${ }^{\circledR}$ (Organon Laboratories Ltd., UK), or urinary hCG Menogon ${ }^{\circledR}$ (Ferring Pharmaceuticals,Istanbul, Turkey) for gonadotropin stimulation. The starting dose was calculated depending on age, BMI and basal antimullerian hormone $(\mathrm{AMH})$ of the patient, as well as on ovarian response in previous cycles, diagnosis and types of diagnostic criteria of PCOS and sonographic appearance of the ovarian function (AFC). Decision was made according to the Dose-Finding-Chart (see below, - Fig.3). The final oocyte maturation was induced with 


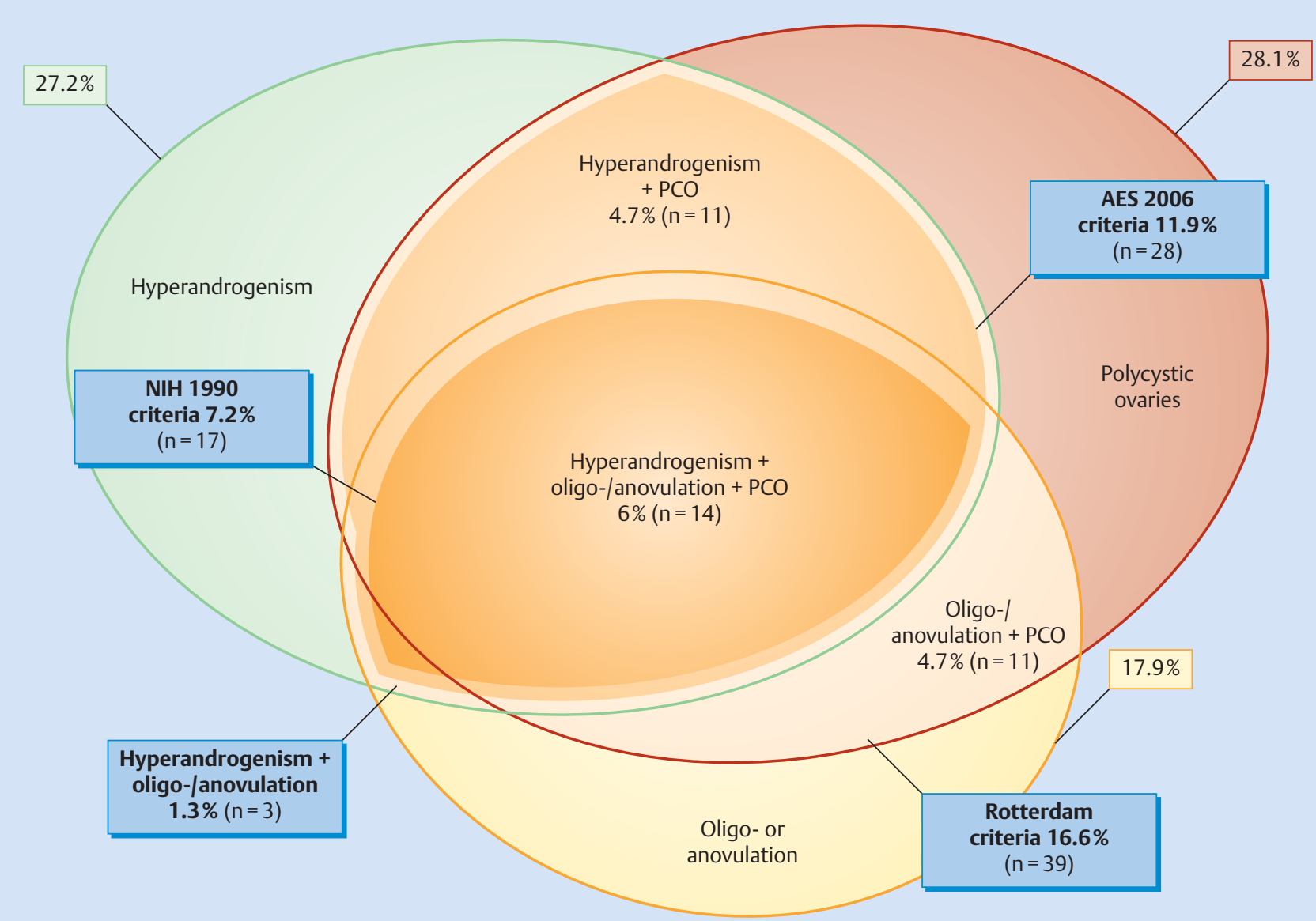

Fig. 1 Distribution of each Rotterdam diagnostic criteria (ellipses), patients fulfilling multiple Rotterdam criteria (overlapping areas) and patients fulfilling $\mathrm{NIH}$-criteria (hyperandrogenism plus oligo-/anovulation) and AES criteria (hyperandrogenism plus oligo-/anovulation or plus typical ultrasound) as percentage of all stimulated women $(n=235)$. Abbreviations: PCO - typical picture of polycystic ovaries in ultrasound, NIH - National Institutes of Health criteria of 1990, AES - Androgen Excess Society criteria of 2006.
10000 IU hCG (Predalon ${ }^{\circledR}$, Brevactid ${ }^{\circledR}$ ) or 250 IE recHCG (Ovitrelle ${ }^{\circledR}$, Merck Serono, MSD). Ultrasound guided oocyte retrieval was performed 36 hours later under general anesthesia.

\section{Biochemical analyses and outcome}

The free androgen index (FAI) was calculated from total testosterone $(\mathrm{nmol} / \mathrm{l}) \times 100 / \mathrm{SHBG}(\mathrm{nmol} / \mathrm{l})$. For the measurement of $\mathrm{LH}$, FSH, estradiol, progesterone, hCG and prolactin sandwich-immunoassay-Kits from ADVIA Centaur ${ }^{\circledR}$, Siemens Healthcare Diagnostics, Inc. (Tarrytown, U.S.A.) were used. Radioimmunoassays for free testosterone (Active ${ }^{\circledR}$ Free testosteron RIA), sex hormone binding globulin (SHBG IRMA KIT), dehydroepiandrosterone sulfat (DHEAS-S-7 RIA) and AMH (AMH Gen II ELISA-Kit) were obtained from Beckman Coulter (Galway, Ireland). Asbach Medical Products $\mathrm{GmbH}$ (Obrigheim, Germany) provided radioimmunoassays RIA CT for 17-OH-progesterone und androstendione. Beginning with the second half of 2013, we used RIA testosterone direct for total testosterone, Active ${ }^{\circledR}$ Free testosterone, Active ${ }^{\circledR}$ androstendion and SHBG IRMA KIT from Beckman Coulter. DHEAS was quantified by radioimmunoassay Immulite ${ }^{\circledR}$ DHEA-SO4 from Siemens Healthcare Diagnostics, Inc. (Tarrytown, U.S.A.) and 17-OH-progesterone by ELISA from IBL INTERNATIONAL GmbH (Hamburg, Germany).

A biochemical pregnancy was confirmed with a serum $\beta$-hCG above $10 \mathrm{E} / \mathrm{l} 12$ to 16 days after ET. A gestational sac four to five weeks after embryo transfer visible on transvaginal ultrasound scan was evaluated as a clinical pregnancy.

\section{Statistical analyses}

Following the analysis of the study population, the PCOS- and control group were described and compared using SPSS Statistics (Version 22.0.0.0). Nominal and ordinal data were characterized by frequency, and compared using a $\mathrm{X}^{2}$ test or Fisher's exact test for smaller sample sizes. Metrical data were analyzed by descriptive statistics. Using the Levene's test confirmed similar variance of the compared groups and allowed the use of Students t-test, otherwise further significance was calculated by Wilcoxon test (Mann-Whitney-U-Test). P $<0.05$ was considered as statistically significant.

\section{Results}

\section{$\nabla$}

Characterization of the study population and collectives The study included 370 stimulation cycles of 235 women treated at the infertility unit of the University Hospital in Dresden within three years. In vitro fertilization (IVF) was performed in $43.8 \%$ of the cycles, intracytoplasmatic sperm injection (ICSI) in $54.9 \%$ of cases, and in the remaining percentage IVF/ICSI splitting was performed. 
Table 2 Patient characteristics of 235 patients treated with controlled stimulation for ART (mean \pm SD) and cycle characteristics of 370 controlled stimulation cycles and outcome of $329 \mathrm{ET}$ (mean \pm SD). Bold font: $p<0,05$, considered as statistically significant.

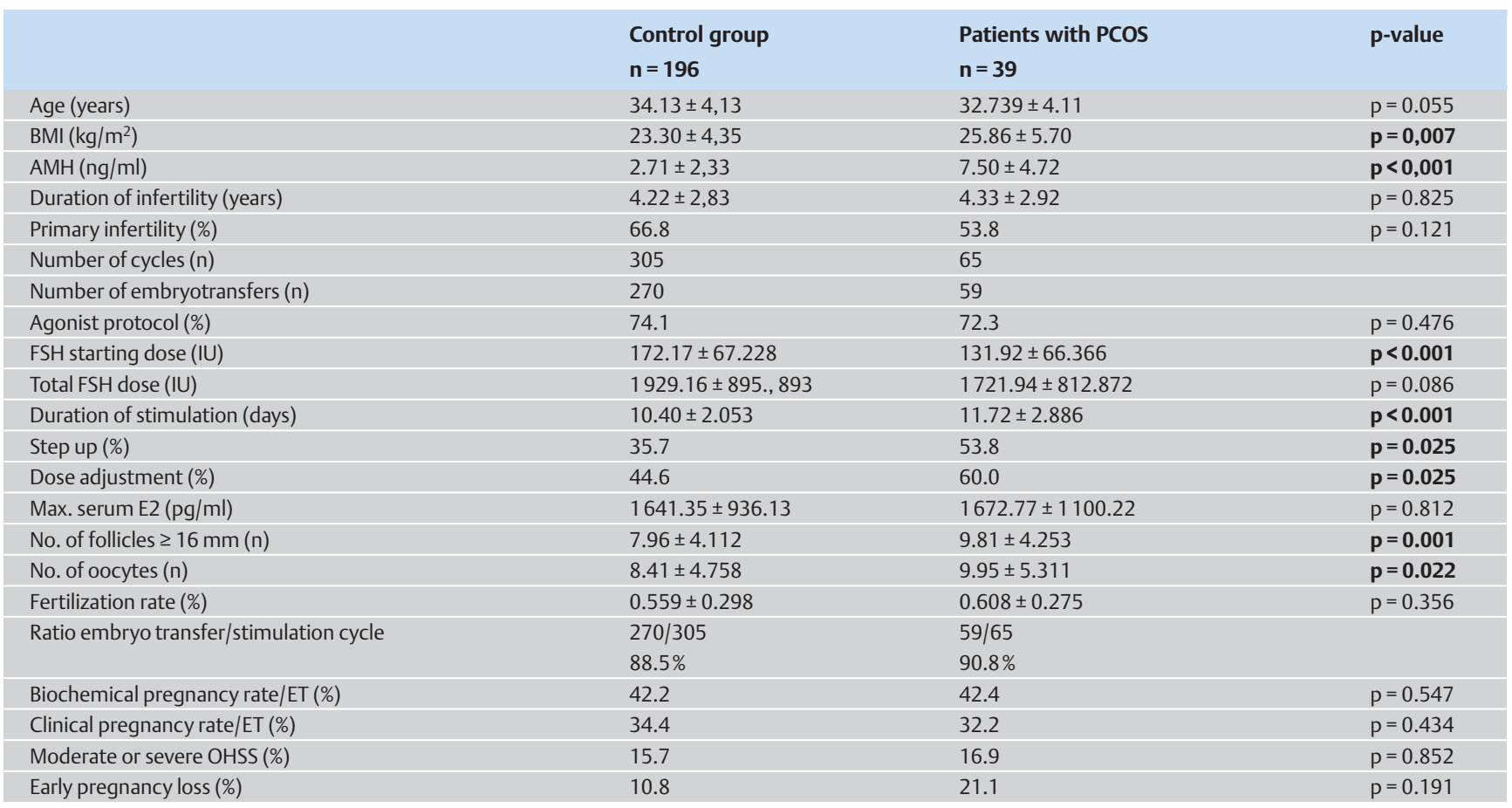

PCOS was diagnosed according to Rotterdam criteria in $16.6 \%$ of patients. If NIH criteria were applied, $7.2 \%$ of the study population were considered having PCOS and with AES criteria $11.9 \%$. The distribution of Rotterdam phenotypes and the classification of FAS of the study group is visualized in 0 Fig. 1. For our study we explicitly differentiate patients in group FAS III with hyperandrogenism, metabolic syndrome, polyfollicular ovaries from FAS IV, because women with FAS III are at higher risk for hyperstimulation. FAS IV group women also show metabolic syndrome and hyperandrogenism but ovaries with normal or even low ovarian reserve. In terms of fertility treatment, those patients often perform as low responders in controlled ovarian hyperstimulation. Therefore we decided to use in this study the Rotterdam criteria to select the study group.

Characteristics of the study groups are shown in 0 Table 2 , as well as differences in stimulation regime, ovarian response and outcome. The mean age in both groups was not statistically different. Mean BMI and AMH-levels were significantly higher in the PCOS-group.

One cycle had to be canceled for impending hyperstimulation and there was no oocyte retrieval performed after hormonal stimulation in one case because of the absence of sperms after testicular sperm extraction.

\section{Stimulation modality depending on AMH-level}

Classifying our cycles into AMH-responder groups a positive trend of the portion of cycles with PCOS diagnosis, polycystic ovarian morphology and oligo- or amenorrhea between the AMH-groups becomes visible $\left(X^{2}\right.$ test, all $p<0.001$ ). This does not apply using the criteria of hyperandrogenaemia as a predictor of response $(\mathrm{p}=0.066)$.

The mean FSH-starting and maximum dose, as well as the total dose of FSH differed within the AMH-responder groups, declining by rising AMH-levels (ANOVA p < 0.001) (@ Fig. 2).
Splitting the basal AMH-value of excessive responders into additional subgroups, the occurrence of each manifestation of the OHSS is not significant ( $\mathrm{p}$-value for mild $\mathrm{p}=0.765$; moderate $\mathrm{p}=0.144$ and severe $\mathrm{p}=0.097$ ). But on pooling moderate or severe manifestation a significant increase with higher AMH-values becomes visible $(p=0.005)$ ( $\bullet$ Fig. 2 ). Significantly more follicles developed, higher estradiol levels were reached and oocytes could be retrieved within more sensitive groups (ANOVA all pvalues $<0.001$ ).

\section{Outcome}

In our study the biochemical pregnancy rate of all patients per ET was $42.2 \%$ and the clinical pregnancy rate per ET $34.0 \%$. The biochemical pregnancy rate of $42.4 \%$ and the clinical pregnancy rate of $32.2 \%$ for PCOS-patients did not differ statistically from those of the control group. $32.1 \%$ of all clinical pregnancies were twins, there were no higher multiple pregnancies. Two cases of ectopic pregnancy occurred and $12.5 \%$ of clinical pregnancies aborted. Miscarriage rate was similar in both groups ( Table 2 ).

A mild OHSS occurred in 3.5\%, moderate in $8.4 \%$ and severe in $7.6 \%$ of all stimulation cycles, which resulted in the need for hospitalization for $1.9 \%$ of treatments. All seven patients hospitalized for OHSS had no prior diagnosis of PCOS, and hospitalization does not differ between study groups $(p=0.611)$. Neither a mild, nor a moderate or severe manifestation of OHSS occurred significantly more often in patients diagnosed with PCOS. Albeit, in the PCOS collective, one stimulation cycle (all PN-oocytes) was cryopreserved without fresh-embryo transfer (freeze all) and one cycle was coasted because of impending OHSS.

\section{Analysis of the Rotterdam phenotypes}

Highest basal AMH-levels can be found for the phenotype with expression of all three features of the Rotterdam criteria. With 


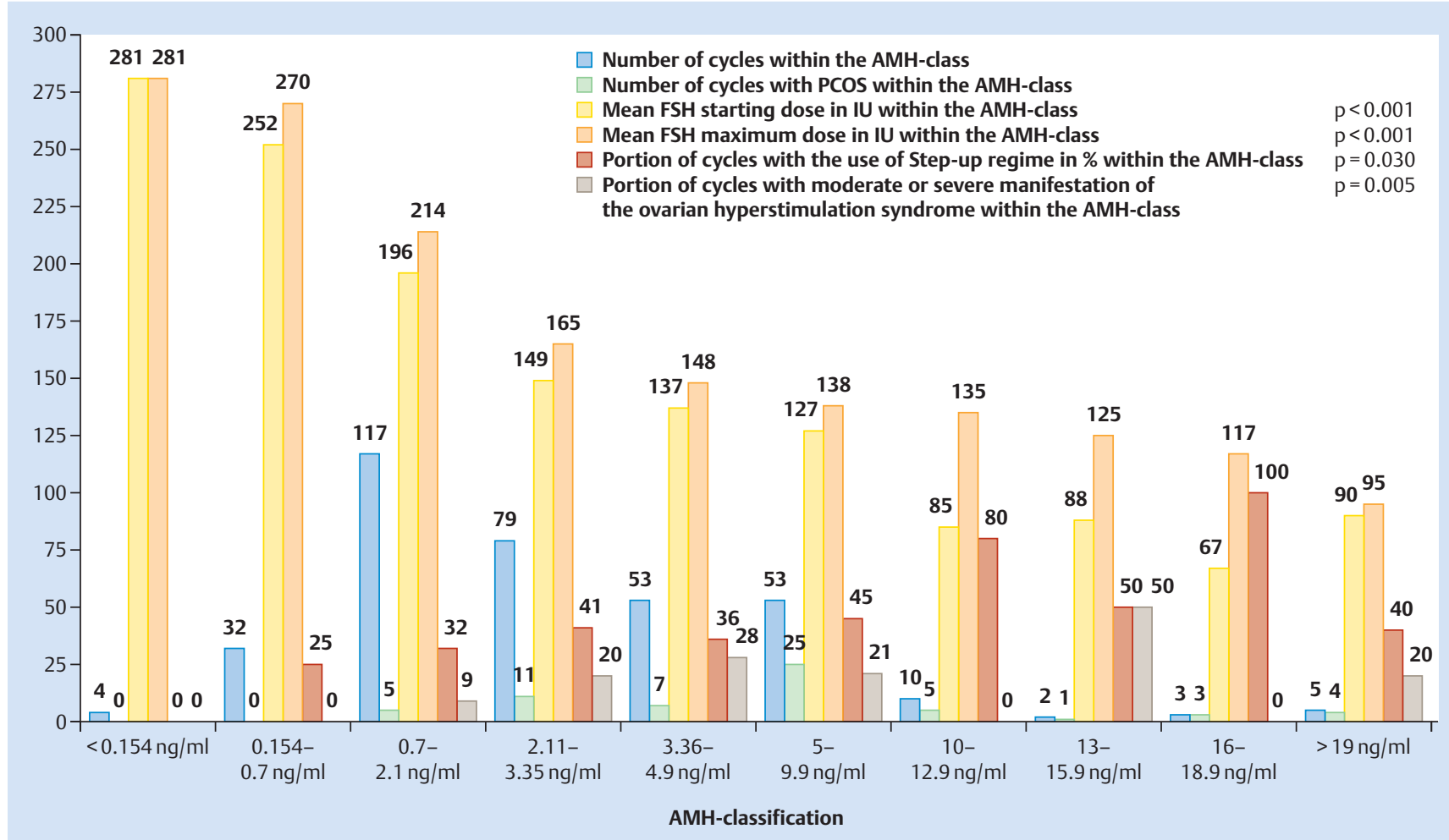

Fig. 2 Illustration of the total number of cycles and the number of cycles with PCOS within the AMH-Class, applied FSH-starting-and maximum doses, cycles with the use of the step-up-regimen and occurrence of moderate or severe ovarian hyperstimulation syndrome within each class.

$45 \%$, this group accounted for the largest proportion of all cycles of PCOS patients.

For PCOS-patients with oligo- or anovulation and polycystic ovarian morphology, we applied the lowest mean FSH dose (98 IU). Starting dose of the type with hyperandrogenism and oligo- or anovulation is biased by one patient with three stimulation cycles, accounting for one third of all cycles within this group. Her AMH-level was $1.35 \mathrm{ng} / \mathrm{ml}$, aged 41-44 years and her BMI $32 \mathrm{~kg} / \mathrm{m}^{2}$. In this case, we decided to start with 200-300 IU. For the Rotterdam phenotype with hyperandrogenism and polycystic ovarian morphology as well as for the phenotype with expression of all criteria, moderate and severe OHSS occurred in more than $10 \%$ of cycles. Nevertheless, the distribution of several manifestations of the OHSS shows no significant deviation of the Gaussian distribution ( Table 3).

\section{Discussion \\ $\nabla$}

Clinical pregnancy rates after ART of women with PCOS differ between 22 and $42 \%$ in literature all over the world. This wide spectrum of pregnancy rates is due to different patients' characteristics and treatment methods. Furthermore there are worldwide differing strategies for artificial reproduction with variations of number of transferred embryos, using blastocyst culture and elective single embryo-transfer or pre-implantation genetic diagnosis.

Nevertheless compared to the literature, our calculated stimulation regime represents a feasible option for both PCOS and NonPCOS patients, with a satisfying result of $34.0 \%$ clinical pregnancy rate per embryo transfer.
By investigating patients with and without PCOS diagnosed by Rotterdam criteria, we could not find a difference in the clinical pregnancy rate, confirming results of other authors [10-12]. Results were comparable for PCOS patients, despite significantly higher BMI values compared to the control group, which essentially impairs fertility treatment outcomes $[13,14]$. Our PCOS study population had a mean BMI of $25,9 \mathrm{~kg} / \mathrm{m}^{2}$, which is considered overweight according to WHO and confirmed this observation.

The proposed stimulation regime with calculated low-dose stimulation for PCOS did not show elevated frequency of OHSS. Moderate or severe OHSS occurred in $8.4 \%$ and in $7.6 \%$ of all stimulation cycles and ranges within the rates in literature (5 to $16.6 \%$ $[10,15,16])$. However, lean body weight and low BMI in PCOS increases the OHSS risk $[17,18]$. Interestingly in our study the need for hospitalization exclusively affected patients without PCOS. Although the absolute number of women with OHSS in all groups was low, the higher awareness for OHSS in women with PCOS and anticipated risk may have resulted in this reduction of risks.

To prevent OHSS, in one case we decided to reduce drastically the gonadotropin dose ("coasting") and in another case we froze all fertilized oocytes without fresh ET. Both treatments were applied to the same patient in subsequent stimulation cycles. The women showed extreme sensitivity to gonadotropins in two following cycles, thus representing a potential candidate for in vitro maturation.

Concerning spontaneous miscarriage rates of patients with PCOS conceiving with ART, most studies did not show a significantly elevated miscarriage rate for women with this diagnosis $[19,20]$. Corresponding to these results, patients treated in our clinic did 
Table 3 Analysis of the Rotterdam phenotypes according to characterization, stimulation modalities and outcome. Bold font: $p<0,05$, considered as statistically significant.

\begin{tabular}{|c|c|c|c|c|c|c|}
\hline & No. PCOS & $\begin{array}{l}\text { Hyperandro- } \\
\text { genism + oligo-I } \\
\text { anovulation }\end{array}$ & $\begin{array}{l}\text { Hyperandro- } \\
\text { genism + PCO }\end{array}$ & $\begin{array}{l}\text { Oligo- or } \\
\text { anovulation+ } \\
\text { PCO }\end{array}$ & $\begin{array}{l}\text { Hyperandro- } \\
\text { genism + oligo-I } \\
\text { anovulation + PCO }\end{array}$ & p-value \\
\hline Number of patients ( $\mathrm{n}$ ) & 196 & 3 & 11 & 11 & 14 & \\
\hline Number of cycles ( $n$ ) & 305 & 10 & 14 & 12 & 29 & \\
\hline $\begin{array}{l}\text { Portion of cycles of the } \\
\text { phenotype (\%) }\end{array}$ & 82.4 & 2.7 & 3.8 & 3.2 & 7.8 & \\
\hline $\begin{array}{l}\text { Portion of cycles with } \\
\text { PCOS (\%) }\end{array}$ & & 15.4 & 21.5 & 18.5 & 44.6 & \\
\hline Mean age (y) & $34.14 \pm 4.13$ & $35.55 \pm 5.20$ & $32.53 \pm 4.01$ & $32.10 \pm 4.75$ & $32.80 \pm 3.65$ & 0.654 \\
\hline Mean BMI $\left(\mathrm{kg} / \mathrm{m}^{2}\right)$ & $23.30 \pm 4.35$ & $29.90 \pm 1.83$ & $25.49 \pm 4.87$ & $26.18 \pm 6.56$ & $25.01 \pm 6.15$ & 0.613 \\
\hline $\begin{array}{l}\text { Mean basal AMH-level } \\
(\mathrm{ng} / \mathrm{ml})\end{array}$ & $2.71 \pm 2.33$ & $3.71 \pm 3.68$ & $5.61 \pm 1.83$ & $7.44 \pm 4.76$ & $9.84 \pm 5.55$ & 0.061 \\
\hline $\begin{array}{l}\text { Portion of cycles with } \\
\text { step-up regimen (\%) }\end{array}$ & $109(35.7 \%)$ & $3(30 \%)$ & $6(42.9 \%)$ & $7(58.3 \%)$ & $19(65.5 \%)$ & 0.132 \\
\hline $\begin{array}{l}\text { Portion without dose } \\
\text { adjustment (\%) }\end{array}$ & $169(55.4 \%)$ & $6(60 \%)$ & $7(50 \%)$ & $4(33.3 \%)$ & $9(31.0 \%)$ & 0.132 \\
\hline $\begin{array}{l}\text { Portion of cycles with use } \\
\text { of oral contraceptives (\%) }\end{array}$ & $28(9.2 \%)$ & $2(20 \%)$ & $0 \%$ & $1(8.3 \%)$ & $14(48.3 \%)$ & $<0.001$ \\
\hline $\begin{array}{l}\text { Portion of cycles with } \\
\text { agonist protocol (\%) }\end{array}$ & $226(74.1 \%)$ & $6(60 \%)$ & $12(85.7 \%)$ & $10(83.3 \%)$ & $19(65.5 \%)$ & 0.419 \\
\hline $\begin{array}{l}\text { Mean FSH-Starting } \\
\text { dose (IU) }\end{array}$ & $172.17 \pm 67.23$ & $245.00 \pm 48.31$ & $110.71 \pm 27.24$ & $97.92 \pm 29.11$ & $117.24 \pm 55.94$ & $<0.001$ \\
\hline Mean total FSH dose (IU) & $1929.16 \pm 895.89$ & $2937.50 \pm 976.69$ & $1341.07 \pm 342.59$ & $1370.83 \pm 596.76$ & $1631.93 \pm 589.78$ & $<0.001$ \\
\hline $\begin{array}{l}\text { Mean endstimulatory } \\
\text { estradiol level (pg/ml) }\end{array}$ & $1641.35 \pm 936.127$ & $1140.80 \pm 856.31$ & $1957.86 \pm 1092.07$ & $1573.42 \pm 853.66$ & $1759.69 \pm 1239.89$ & 0.323 \\
\hline $\begin{array}{l}\text { Portion of cycles with } \\
\text { mild OHSS (\%) }\end{array}$ & $12(3.9 \%)$ & 0 & 0 & 0 & $1(3.4 \%)$ & 0.832 \\
\hline Moderate OHSS (\%) & $25(8.2 \%)$ & 0 & $3(21.4 \%)$ & 0 & $3(10.3 \%)$ & 0.260 \\
\hline Severe OHSS (\%) & $23(7.5 \%)$ & 0 & $1(7.1 \%)$ & $1(8.3 \%)$ & $3(10.3 \%)$ & 0.886 \\
\hline
\end{tabular}

not show a difference. Nevertheless higher BMI and PCOS may contribute additionally to the elevated miscarriage rate [21,22]. For PCOS, studies report higher numbers of developing follicles and aspirated oocytes compared to controls [10,23-26]. Similarly, our PCOS group showed significantly higher average numbers of follicles and retrieved oocytes although we used lower FSH-doses as usually recommended in our controlled stimulation protocol. Primarily, outcome parameters are rising with the extent of the reaction to gonadotropin stimulation, coming to a plateau and decreasing with stronger response to stimulation. Decreasing pregnancy [27] and live birth rates [16] are reported when more than 15 oocytes were aspirated. Lower doses of gonadotropins lead to smaller reactions, which would be in favour of more sensitive patients like those with PCOS.

The FAS-classification proposed by Geisthövel [3] differentiates the subgroup of women with hyperandrogenemia and response to COS into high and low response. Our data show, that patients in group FAS III, which show hyperandrogenism, metabolic syndrome and polyfollicular/polycystic ovaries are at risk for ovarian hyperstimulation. On the contrary women with FAS IV - even though hyperandrogenism is present - are at risk for low response. Gonadotropins should be adapted to the parameter of ovarian reserve, $\mathrm{AMH}$ and $\mathrm{AFC}$.

Analysing applied doses in our regime, adjustments and experiences in literature, we come to the following Dose-Finding-Chart for the FSH-starting dose ( Fig. 3).

On average after calculating the individual dose, we started stimulation with 132 IU FSH in PCOS-patients. Though individually adjusted, it can be necessary to lower this dose down to 75 IU.
These doses range below the doses of the "mild stimulation" established by the group around Fauser et al. [28]. Despite our lowdose strategy, our results are not inferior to those in literature in terms of outcome and risks.

Nelson et al. [6] and Yates et al. [29] recommended an AMHstratified approach for the decision of the stimulation protocol and FSH dose. For extreme responders (according to AMH above $2 \mathrm{ng} / \mathrm{ml}$ and Yates above $3.9 \mathrm{ng} / \mathrm{ml}$ ) they suggest choosing the antagonist protocol, because cycle cancelation rate is lower and risk of OHSS is already reduced with this type of protocol. From this cut-off, both authors started with a dose of $150 \mathrm{IU}$ FSH/d. Also for extremely low responders, below 0.14 resp. $0.3-2.1 \mathrm{ng} / \mathrm{ml}$, both recommend the antagonist protocol.

In the study of Gera, for cycles with estradiol levels above $2500 \mathrm{pg} / \mathrm{ml}$ or more than 30 growing follicles, coasting and if necessary elective oocyte or embryo cryopreservation and subsequent transfer in a hormonal prepared cryo-cycle were initiated. In this publication, the incidence of OHSS is lowered without impairing pregnancy- and live birth rate [30].

Steward emphasizes the need of less aggressive stimulation strategies for patients at risk and refers to the method of the GnRH-antagonist-protocol with the agonist-trigger [16].

Besides intensive support with administration of progesterone and E2 and the separation of the stimulation cycle and oocyte pick-up from the ET, the investigation group of Humaidan, Engmann and Benadiva refined the strategies against the impairment of endometrial quality by luteolysis. They suggest additional support of the luteal phase with low-dose hCG-injections and fresh ET and reached comparable results for clinical and ongoing 


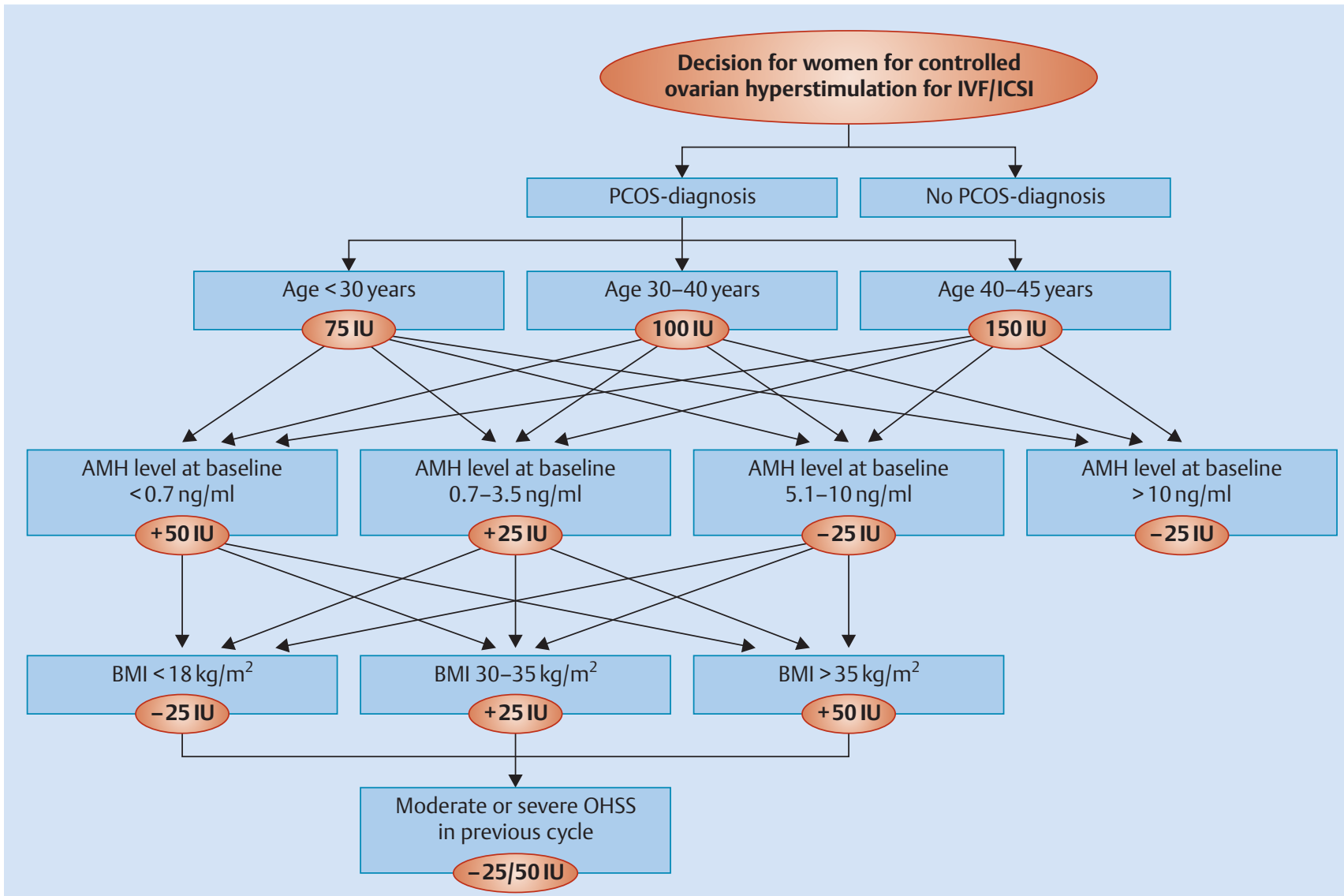

Fig. 3 Dose finding algorithm for PCOS patient.

pregnancy rates as well as OHSS rates in a randomized controlled trail compared to hCG-trigger. For very high-risk patients responding with more than 25 follicles, they still chose to freeze all embryos and transfer in a subsequent cycle [31,32]. A combination of this strategy and a clear recommendation for an individually adjusted low-dose stimulation is conceivable. Nevertheless, despite the use of GnRH-agonist-trigger and low-dose hCG luteal support, for patients under elevated risk, up to $26 \%$ severe OHSS were seen when fresh ET was performed [33].

Abstaining from exogenous hCG luteal support and choosing elective cryopreservation instead of a fresh transfer improves safety of controlled ovarian stimulation for patients at high risk, at the price of lower pregnancy rates [34]. However, even with those preventive measures, six cases of severe OHSS are reported [35-37]. It seems that up to date there is no complete and effective prevention of OHSS. In the case of Ling, the patient showed basal serum AMH level of $64.5 \mathrm{ng} / \mathrm{ml}$ and developed more than 40 follicles [37]. Also in the case reports of Gurbuz, one instance of 27 and another one of 52 follicles with 45 retrieved oocytes and serum estradiol levels above 5985 and 10904 pg/ml were observed [36]. All cases show that even without endogenous hCG rising in early pregnancy after fresh ET, early-onset OHSS can occur with any kind of gonadotropin administration. If IVM cycles are primed with 125 IU FSH and ovulation is triggered by exogenous hCG as previously described [34,38], theoretically the risk of OHSS is even existing with "safe" low-dose IVM-strategy.
There is no strategy to prevent completely the risk of OHSS when gonadotropins are used. On the other hand, very sensitive patients with extremely exaggerated ovarian responses to gonadotropins are extremely rare. The challenge is to identify those patients who are at risk with the well-established approaches and offer the chance to use selectively the safe alternative of IVM. Most fertility centers in the world do not offer the reserve method of IVM. Establishment of IVM techniques and laboratory expertise is for the majority of IVF-centers inaccessible and not cost-effective. Studies show that the technique is feasible, although a longer time of training is required $[38,39]$. A solution could be the improvement of existing techniques and experience with exact recommendations from large RCTs and health institutes. Few, individual centers, offering IVM should get the chance to refine their IVM-techniques and knowledge. The majority of fertility centers should filter those patients for IVM and refer them to centers with special expertise in IVH.

The major drawbacks of our study on individually calculated low dose stimulation for PCOS is the retrospective character and the low number of participants. For a following randomised trial, clear guidance for decision-making should be developed out of these first results. The different phenotypes of Rotterdam diagnosed PCOS should be considered in detail. 


\section{Conclusion for Clinical Practice}

$\nabla$

Patients with PCOS represent a challenge for reproductive medicine. We propose a calculated low-dose stimulation strategy with step-up according to ovarian response in long agonist and antagonist protocols.

The choice of the starting dose of FSH has to be calculated by patients' basal AMH level, AFC, age, BMI and PCOS diagnosis. Response to previous stimulation cycles should be integrated as another important clinical parameter, according to our dose finding algorithm.

\section{Conflict of Interest \\ $\nabla$}

M. Goeckenjan declares reimbursement of traveling expenses by MSD, Merck Serono and Fürring.

\section{References}

1 Tan S. Endokrionologie. Minimaldiagnostik und Therapieansätze beim PCOS. Geburtsh Frauenheilk 2012; 72: 696-700

2 Rotterdam ESHRE/ASRM-Sponsored PCOS Consensus Group. Revised 2003 consensus on diagnostic criteria and long-term health risks related to polycystic ovary syndrome. Fertil Steril 2004; 81: 19-25

3 Geisthövel F. [Functional hyperandrogenism-classification, etiology, diagnosis and therapy]. Ther Umsch 2002; 59: 163-173

4 Cupisti S. Komplikation bei Ovulationsinduktion. Das ovarielle Überstimulationssyndrom. Geburtsh Frauenheilk 2012; 72: 798-801

5 Binder H, Cupisti S, Dittrich $R$ et al. Ovarielles Überstimulationssyndrom-update - Teil 2. Geburtsh Frauenheilk 2004; 64: R77-R100

6 Nelson SM, Yates RW, Lyall $H$ et al. Anti-Müllerian hormone-based approach to controlled ovarian stimulation for assisted conception. Hum Reprod 2009; 24: 867-875

7 Lee TH, Liu CH, Huang CC et al. Serum anti-Mullerian hormone and estradiol levels as predictors of ovarian hyperstimulation syndrome in assisted reproduction technology cycles. Hum Reprod 2008; 23: 160167

8 World Health Organisation. WHO laboratory Manual for the Examination and Processing of human Semen. 5th ed. Geneva: World Health Organisation; 2010: 271

9 Aboulghar MA, Mansour RT. Ovarian hyperstimulation syndrome: classifications and critical analysis of preventive measures. Hum Reprod Update 2003; 9: 275-289

10 Heijnen EM, Eijkemans MJ, Hughes EG et al. A meta-analysis of outcomes of conventional IVF in women with polycystic ovary syndrome. Hum Reprod Update 2006; 12: 13-21

11 Thessaloniki ESHRE/ASRM-Sponsored PCOS Consensus Workshop Group. Consensus on infertility treatment related to polycystic ovary syndrome. Fertil Steril 2008; 89: 505-522

12 Swanton A, Storey L, McVeigh E et al. IVF outcome in women with PCOS, PCO and normal ovarian morphology. Eur J Obstet Gynecol Reprod Biol 2010; 149: 68-71

13 Rittenberg $V$, Seshadri S, Sunkara SK et al. Effect of body mass index on IVF treatment outcome: an updated systematic review and meta-analysis. Reprod Biomed Online 2011; 23: 421-439

14 Bailey AP, Hawkins LK, Missmer SA et al. Effect of body mass index on in vitro fertilization outcomes in women with polycystic ovary syndrome. Am J Obstet Gynecol 2014; 211: 163.e1-163.e6

15 Figen Turkcapar A, Seckin B, Onalan G et al. Human menopausal gonadotropin versus recombinant FSH in polycystic ovary syndrome patients undergoing in vitro fertilization. Int J Fertil Steril 2013; 6: 238-243

16 Steward RG, Lan L, Shah AA et al. Oocyte number as a predictor for ovarian hyperstimulation syndrome and live birth: an analysis of 256,381 in vitro fertilization cycles. Fertil Steril 2014; 101: 967-973

17 Practice Committee of American Society for Reproductive Medicine. Ovarian hyperstimulation syndrome. Fertil Steril 2008; 90: S188-S193
18 Teede HJ, Joham AE, Paul E et al. Longitudinal weight gain in women identified with polycystic ovary syndrome: results of an observational study in young women. Obesity 2013; 21: 1526-1532

19 Beydoun HA, Stadtmauer L, Zhao Y et al. Impact of polycystic ovary syndrome on selected indicators of in vitro fertilization and intracytoplasmic sperm injection treatment success. J Womens Health (Larchmt) 2009; 18: 717-723

20 Liu L, Tong X, Jiang L et al. A comparison of the miscarriage rate between women with and without polycystic ovarian syndrome undergoing IVF treatment. Eur J Obstet Gynecol Reprod Biol 2014; 176: 178-182

21 Wang JX, Davies MJ, Norman RJ. Polycystic ovarian syndrome and the risk of spontaneous abortion following assisted reproductive technology treatment. Hum Reprod 2001; 16: 2606-2609

22 Ozgun MT, Uludag S, Oner G et al. The influence of obesity on ICSI outcomes in women with polycystic ovary syndrome. J Obstet Gynaecol 2011; 31: 245-249

23 Esinler I, Bayar U, Bozdag G et al. Outcome of intracytoplasmic sperm injection in patients with polycystic ovary syndrome or isolated polycystic ovaries. Fertil Steril 2005; 84: 932-937

24 Sahu B, Ozturk O, Ranierri M et al. Comparison of oocyte quality and intracytoplasmic sperm injection outcome in women with isolated polycystic ovaries or polycystic ovarian syndrome. Arch Gynecol Obstet 2008; 277: 239-244

25 McCormick B, Thomas M, Maxwell R et al. Effects of polycystic ovarian syndrome on in vitro fertilization-embryo transfer outcomes are influenced by body mass index. 2008. Fertil Steril 2008; 90: 2304-2309

26 Swanton A, Storey L, McVeigh E et al. IVF outcome in women with PCOS, PCO and normal ovarian morphology. Eur J Obstet Gynecol Reprod Biol 2010; 149: 68-71

27 Hamdine O, Eijkemans MJ, Lentjes EW et al. Ovarian response prediction in GnRH antagonist treatment for IVF using anti-mullerian hormone. Hum Reprod 2015; 30: 170-178

28 Fauser BC, Nargund G, Andersen AN et al. Mild ovarian stimulation for IVF: 10 years later. Hum Reprod 2010; 25: 2678-2684

29 Yates AP, Rustamov 0, Roberts SA et al. Anti-mullerian hormone-tailored stimulation protocols improve outcomes whilst reducing adverse effects and costs of IVF. Hum Reprod 2011; 26: 2353-2362

30 Gera PS, Tatpati LL, Allemand MC et al. Ovarian hyperstimulation syndrome: Steps to maximize success and minimize effect for assisted reproductive outcome. Fertil Steril 2010; 94: 173-178

31 Humaidan P, Polyzos NP, Alsbjerg B et al. GnRHa trigger and individualized luteal phase hCG support according to ovarian response to stimulation: two prospective randomized controlled multi-centre studies in IVF patients. Hum Reprod 2013; 28: 2511-2521

32 Humaidan P, Engmann L, Benadiva C. Luteal phase supplementation after gonadotropin-releasing hormone agonist trigger in fresh embryo transfer: The American versus European approaches. Fertil Steril 2015; 103: 879-885

33 Seyhan A, Ata B, Polat $M$ et al. Severe early ovarian hyperstimulation syndrome following GnRH agonist trigger with the addition of 1500 IU hCG. Hum Reprod 2013; 28: 2522-2528

34 von Wolff M, Eberhardt I, Strowitzki T. In-vitro-Maturation - Indikationen, Risiken und Chancen einer neuen assistierten Reproduktionstechnik. Geburtsh Frauenheilk 2009; 67: 734-741

35 Fatemi HM, Popovic-Todorovic B, Humaidan P et al. Severe ovarian hyperstimulation syndrome after gonadotropin-releasing hormone $(\mathrm{GnRH})$ agonist trigger and "freeze-all" approach in GnRH antagonist protocol. Fertil Steril 2014; 101: 1008-1011

36 Gurbuz AS, Gode F, Ozcimen N et al. Gonadotrophin-releasing hormone agonist trigger and freeze-all strategy does not prevent severe ovarian hyperstimulation syndrome: a report of three cases. Reprod Biomed Online 2014; 29: 541-544

37 Ling LP, Phoon JW, Lau MS et al. GnRH agonist trigger and ovarian hyperstimulation syndrome: Relook at 'freeze-all strategy'. Reprod Biomed Online 2014; 29: 392-394

38 von Otte S, Griesinger G, Schultze-Mosgau A et al. Die Etablierung der Invitro-Maturation als neue Variante der assistierten Reproduktion - Erfahrungen der Lübecker Arbeitsgruppe. Geburtsh Frauenheilk 2007; 67: 1009-1017

39 Roesner S, von Wolff M, Eberhardt I et al. In vitro maturation: a five-year experience. Acta Obstet Gynecol Scand 2012; 91: 22-27 